Systematic Review

\title{
Is There a Benefit of Oxaliplatin in Combination with Neoadjuvant Chemoradiotherapy for Locally Advanced Rectal Cancer? An Updated Meta-Analysis
}

\author{
Gaëtan Des Guetz ${ }^{1,2, *}$, Thierry Landre ${ }^{3} \mathbb{D}$, Marc A. Bollet ${ }^{4}$, Muriel Mathonnet ${ }^{2,5}\left(\mathbb{D}\right.$ and Laurent Quéro ${ }^{6,7}(\mathbb{D})$ \\ 1 Medical Oncology Department, Delafontaine Hospital, 93200 St Denis, France \\ 2 Department of Surgery, Faculty of Medicine, University of Limoges, 87032 Limoges, France; \\ muriel.mathonnet@unilim.fr \\ 3 Unité de Coordination en Onco-Gériatrie, Hôpitaux Universitaires Paris Seine-St-Denis, \\ AP-HP, 93270 Sevran, France; thierry.landre@aphp.fr \\ 4 Centre de Radiothérapie Hartmann, 92300 Levallois-Perret, France; marc.bollet@horg.fr \\ 5 Department of Surgery, University Hospital of Limoges, 87032 Limoges, France \\ 6 INSERM U1160, Université de Paris, 75010 Paris, France; laurent.quero@aphp.fr \\ 7 Radiation Oncology Department, Saint-Louis University Hospital, AP-HP, 75010 Paris, France \\ * Correspondence: gaetan.desguetz@ch-stdenis.fr; Tel.: +33-787006919
}

check for updates

Citation: Des Guetz, G.; Landre, T.; Bollet, M.A.; Mathonnet, M.; Quéro, L. Is There a Benefit of Oxaliplatin in Combination with Neoadjuvant Chemoradiotherapy for Locally Advanced Rectal Cancer? An Updated Meta-Analysis. Cancers 2021, 13, 6035. https://doi.org/10.3390/ cancers13236035

Academic Editor: Massimo Di Maio

Received: 20 September 2021 Accepted: 26 November 2021 Published: 30 November 2021

Publisher's Note: MDPI stays neutral with regard to jurisdictional claims in published maps and institutional affiliations.

Copyright: (c) 2021 by the authors. Licensee MDPI, Basel, Switzerland. This article is an open access article distributed under the terms and conditions of the Creative Commons Attribution (CC BY) license (https:// creativecommons.org/licenses/by/ $4.0 /)$.
Simple Summary: Neoadjuvant fluoropyrimidine (5FU or capecitabine)-based chemoradiotherapy (CRT) has been considered the standard of care for locally advanced rectal cancer (LARC). Our Meta-analysis showed that the combining oxaliplatin with capecitabine or 5FU in preoperative chemoradiotherapy or perioperative chemotherapy seems beneficial significantly and improved DFS. It remains necessary to identify which patients benefit most from the addition of oxaliplatin.

Abstract: Background: Neoadjuvant fluoropyrimidine (5FU or capecitabine)-based chemoradiotherapy (CRT) has been considered the standard of care for locally advanced rectal cancer (LARC). Whether addition of oxaliplatin (OXP) will further improve clinical outcomes is still unclear. Methods: To identify clinical trials combining oxaliplatin in preoperative CRT or perioperative chemotherapy for LARC published until March 2021, we searched PubMed and the Cochrane Library. We also searched for relevant ASCO conference abstracts. The primary endpoint was disease-free survival (DFS). Data were extracted from every study to perform a meta-analysis using Review Manager (version 5.3). Results: A total of seven randomized clinical trials (ACCORD-12, CARO-AIO-04, FOWARC, JIAO, NSABP, PETACC-6, and STAR-01) with 5782 stage II or III rectal cancer patients were analyzed, including 2727 patients with OXP + 5FU regimen and 3055 patients with 5FU alone. Compared with the 5FU alone group, the OXP + 5FU regimen improved DFS (HR = 0.90, 95\% CI: $0.81-0.99, p=0.03)$ and pathologic complete response (pCR) (OR $=1.21,95 \%$ CI: $1.07-1.37, p=0.002)$. Patients treated with the OXP $+5 \mathrm{FU}$ regimen had significantly less metastatic progression $(\mathrm{OR}=0.79$; $95 \% \mathrm{CI}, 0.67$ to $0.94 ; p=0.007$ ). Considering adverse events (AEs), there was more grade $3-4$ diarrhea with OXP + 5FU (OR = 2.41, 95\% CI: 1.74-3.32, $p<0.00001)$. However, there were no significant differences grade 3-4 hematologic AEs (OR = 1.16, 95\% CI: $0.87-1.57, p=0.31$ ). Conclusions: Our meta-analysis with long-term results from the randomized studies showed a benefit of the addition of OXP + 5FU regiment in terms of DFS, metastatic progression, and pCR rate that did not translate to improved OS.

Keywords: meta-analysis; randomized; rectal; radiotherapy; oxaliplatin; neoadjuvant

\section{Introduction}

Colorectal cancer (CRC) is the third most deadly and fourth most commonly diagnosed cancer in the world according to GLOBOCAN 2018 data. Nearly 2 million new cases and about 1 million deaths were observed in 2018 [1]. The treatment of locally advanced 
rectal cancer has long been based on surgery with total mesorectal excision following chemoradiotherapy [2].

This therapeutic strategy made it possible to reduce the rate of loco-regional recurrence without, unfortunately, reducing the rate of distant metastatic recurrence, which remained high at around $30 \%[2,3]$. This lack of efficacy in distant metastatic control could be explained by an insufficient dose-intensity/activity of fluoropyrimidine-based chemotherapy administered concomitantly with radiotherapy to control the micrometastatic disease. Oxaliplatin has been shown to be effective in the treatment of metastatic colorectal cancer and also in the adjuvant treatment of colon cancer. Moreover, oxaliplatin can also act as a radiosensitizer agent [4].

Based on these promising data, several randomized trials have been conducted to evaluate the efficacy of adding oxaliplatin to fluoropyrimidine-based chemoradiotherapy. Because of the inconsistent results of these trials, several meta-analyses have been carried out, but they have not been conclusive [5-10].

Following the recent update of the FOWARC and PETACC-6 clinical trials, we conducted an updated meta-analysis. The primary endpoint of this meta-analysis was to evaluate the benefit of the addition of oxaliplatin-based chemotherapy to concurrent fluoropyrimidine-based chemoradiotherapy and its impact on disease-free survival.

\section{Patients and Methods}

\subsection{Literature Search}

PubMed and Cochrane databases were screened on 30 May 2021. MeSH terms were used throughout the search schemes, which were adjusted appropriately in various electronic records. We also manually searched the abstracts accepted for the following major academic conferences: ESMO (European Society for Medical Oncology), ESTRO (Euro-pean Society for Radiation Oncology), ASCO (American Society of Clinical Oncology), ASTRO (American Society for Radiation Oncology), and ESSO (European Society of Surgical Oncology) until May 2021.

\subsection{Trial Selection}

The methodological quality of the selected studies was evaluated by two authors (T.L. and L.Q.). The trial selection process is documented by a PRISMA flow diagram giving specific reasons for exclusion of studies at each stage (Figure A1). We restricted the search to RCTs comparing neoadjuvant chemoradiotherapy with oxaliplatin added to 5 -fluorouracil or capecitabine. Exclusion criteria were non-phase III randomized studies, letters, comments, and editorials and publications for which the full text was irretrievable. In case of multiple publications on a single clinical trial, all publications were included, and the all results were used with priority given to those with the longest follow-up.

\subsection{Outcome Measures}

The main outcome was disease-free survival. Additional parameters included local recurrence, metastatic progression, pathological complete response, pathological complete resection, postoperative complication rate, toxicity, and overall survival.

\subsection{Statistical Analysis}

The analyses were conducted according to the Cochrane method for meta-analyses and computed with Review Manager software (RevMan version 5.3; Oxford, UK). Hazard ratios (HR) were pooled in meta-analyses by the inverse variance method. Risk ratios (RR) and 95\% confidence intervals (CI) were calculated for count data. $\mathrm{I}^{2}$ and $\mathrm{Chi}^{2}$ tests were used to assess studies-shared heterogeneity. A fixed-effects model was used when between-study heterogeneity was weak. When heterogeneity was strong, a randomized model was used. All tests were bilateral, with $p<0.05$ defining statistical significance. 


\section{Results}

Our meta-analysis included seven trials, with a total of 5782 patients: STAR-01 trial [11], ACCORD12/0405 trial [12-14], NSABP R-04 trial [15,16], CAO/ARO/AIO-04 trial [17], LIAONING CANCER HOSPITAL (JIAO) trial [18], FOWARC trial [19], and PETACC-6 trial [20].

Patient characteristics, including age, gender, clinical $\mathrm{T}$ and $\mathrm{N}$ staging, and tumor location, were well balanced between groups (Table 1).

Table 1. Characteristics of included studies.

\begin{tabular}{|c|c|c|c|c|c|c|c|}
\hline Study & Year & Country & Patients (n) & Radiotherapy & Concurrent Chemotherapy & Adjuvant Chemotherapy & Median F/U \\
\hline NSABP-R04 & 2015 & USA & $\begin{array}{c}\text { Control }=949 \\
\operatorname{Exp}=659\end{array}$ & $\begin{array}{l}45 \mathrm{~Gy} \text { or } 50.4 \mathrm{~Gy} \text { or } 55.8 \mathrm{~Gy} \\
(5 \times 1.8 \mathrm{~Gy} / \mathrm{w})\end{array}$ & $\begin{array}{c}\text { Control: } 5 \mathrm{FU} 225 \mathrm{mg} / \mathrm{m}^{2} / \mathrm{d} \text { or CaP } 825 \mathrm{mg} / \mathrm{m}^{2} \times 2 / \mathrm{d} \\
\text { Exp: } 5 \mathrm{FU} 225 \mathrm{mg} / \mathrm{m}^{2} / \mathrm{d} \text { or CaP } 825 \mathrm{mg} / \mathrm{m}^{2} \times 2 / \mathrm{d}+ \\
\text { oxaliplatin } 50 \mathrm{mg} / \mathrm{m}^{2} / \mathrm{w}\end{array}$ & NR & NR \\
\hline STAR-01 & 2016 & Italy & $\begin{array}{c}\text { Control }=379 \\
\operatorname{Exp}=368\end{array}$ & $50.4 \mathrm{~Gy}(5 \times 1.8 \mathrm{~Gy} / \mathrm{w})$ & $\begin{array}{c}\text { Control: } 5 \mathrm{FU} 225 \mathrm{mg} / \mathrm{m}^{2} / \mathrm{d} \\
\text { Exp: } 5 \mathrm{FU} 225 \mathrm{mg} / \mathrm{m}^{2} / \mathrm{d}+\text { oxaliplatin } 60 \mathrm{mg} / \mathrm{m}^{2} / \mathrm{w} \times 6 \mathrm{w}\end{array}$ & 5FU-based & 105.6 months \\
\hline FOWARC & 2019 & China & $\begin{array}{c}\text { Control }=165 \\
\operatorname{Exp}=165\end{array}$ & $\begin{array}{l}46.0 \mathrm{~Gy}(5 \times 2 \mathrm{~Gy} / \mathrm{w}) \text { or } \\
50.4 \mathrm{~Gy}(5 \times 1.8 \mathrm{~Gy} / \mathrm{w})\end{array}$ & $\begin{array}{l}\text { Control: leucovorin } 400 \mathrm{mg} / \mathrm{m}^{2} 5 \mathrm{FU} \text { bolus } 400 \mathrm{mg} / \mathrm{m}^{2}+5 \mathrm{FU} \\
\qquad 2400 \mathrm{mg} / \mathrm{m}^{2} \mathrm{~d} 1-\mathrm{d} 2 / 2 \mathrm{w} \\
\text { Exp: leucovorin } 400 \mathrm{mg} / \mathrm{m}^{2} 5 \mathrm{FU} \text { bolus } 400 \mathrm{mg} / \mathrm{m}^{2}+5 \mathrm{FU} 2400 \\
\mathrm{mg} / \mathrm{m}^{2} \mathrm{~d} 1-\mathrm{d} 2 / 2 \mathrm{w}+\text { oxaliplatin } 85 \mathrm{mg} / \mathrm{m}^{2} / 2 \mathrm{w}\end{array}$ & mFOLFOX $6 \times 6$ cycles & 45.2 months \\
\hline ACCORD-12 & 2017 & France & $\begin{array}{c}\text { Control }=293 \\
\text { Exp }=291\end{array}$ & $\begin{array}{c}\text { Control: } 45 \mathrm{~Gy} \\
(5 \times 1.8 \mathrm{~Gy} / \mathrm{w}) \\
\text { Exp: } 50 \mathrm{~Gy}(5 \times 2 \mathrm{~Gy} / \mathrm{w})\end{array}$ & $\begin{array}{l}\text { Control: CaP } 800 \mathrm{mg} / \mathrm{m}^{2} \times 2 / \mathrm{d} \\
\text { Exp: CaP } 800 \mathrm{mg} / \mathrm{m}^{2} \times 2 / \mathrm{d}+\text { oxaliplatin } 50 \mathrm{mg} / \mathrm{m}^{2} / \mathrm{w}\end{array}$ & NR & 60.2 months \\
\hline $\mathrm{CAO} / \mathrm{ARO} / \mathrm{AIO}-04$ & 2015 & Germany & $\begin{array}{l}\text { Control }=623 \\
\operatorname{Exp}=613\end{array}$ & $50.4 \mathrm{~Gy}(5 \times 1.8 \mathrm{~Gy} / \mathrm{w})$ & $\begin{array}{l}\text { Control: } 5 \mathrm{FU} 1000 \mathrm{mg} / \mathrm{m}^{2} / \mathrm{d} \mathrm{d} 1-\mathrm{d} 5 \text { and d29-d33 } \\
\text { Exp: } 5 \mathrm{FU} 250 \mathrm{mg} / \mathrm{m}^{2} / \mathrm{d} \text { d1-d14 } \\
\text { and d22-d } 35+\text { oxaliplatin } 50 \mathrm{mg} / \mathrm{m}^{2} / \mathrm{d} \text { d1, d8, d22, d29 }\end{array}$ & $\begin{array}{c}\text { Control: } 5 \mathrm{FU} \text { bolus } 500 \mathrm{mg} / \mathrm{m}^{2} \mathrm{~d} \\
\text { 1-dx }(\times 4 \mathrm{cycles}) \\
\text { Exp: oxaliplatin } \\
\left.100 \mathrm{mg} / \mathrm{m}^{2} / \mathrm{d} \mathrm{d} 1 \text { and } \mathrm{d} 15\right)+ \\
\text { leucovorin } 400 \mathrm{mg} / \mathrm{m}^{2} / \mathrm{d} \mathrm{d} 1 \text { and } \\
\mathrm{d} 15)+5 \mathrm{FU} 2400 \mathrm{mg} / \mathrm{m}^{2} \\
\mathrm{~d} 1-\mathrm{d} 2 \text { and } \mathrm{d} 15-\mathrm{d} 16\end{array}$ & 50 months \\
\hline PETACC-6 & 2021 & Europe & $\begin{array}{c}\text { Control }=543 \\
\operatorname{Exp}=528\end{array}$ & $\begin{array}{c}45 \mathrm{~Gy} \text { or } 50.4 \mathrm{~Gy} \\
(5 \times 1.8 \mathrm{~Gy} / \mathrm{w})\end{array}$ & $\begin{array}{c}\text { Control: CaP } 825 \mathrm{mg} / \mathrm{m}^{2} \times 2 / \mathrm{d} \text { d1-d } 33 \\
\text { Exp: CaP } 825 \mathrm{mg} / \mathrm{m}^{2} \times 2 / \mathrm{d} \mathrm{d} 1-\mathrm{d} 33+\text { oxaliplatin } 50 \mathrm{mg} / \mathrm{m}^{2} / \mathrm{d} \\
\mathrm{d} 1 \text {, d8, d15, d22 and d29 }\end{array}$ & $\begin{array}{l}\text { Control: CaP } 1000 \mathrm{mg} / \mathrm{m}^{2} \times 2 / \mathrm{d} \\
\text { d1 } 15 \times 6 \text { cycles } \\
\text { Exp: CaP } 1000 \mathrm{mg} / \mathrm{m}^{2} \times 2 / \mathrm{d} \\
\text { d1-15+oxaliplatin } 130 \mathrm{mg} / \mathrm{m}^{2} / \mathrm{d} \\
\text { d1 } \times 6 \text { cycles }\end{array}$ & 68 months \\
\hline Jiao et al. [18] & 2015 & China & $\begin{array}{c}\text { Control }=103 \\
\operatorname{Exp}=103\end{array}$ & 50 Gy $(5 \times 2$ Gy $/ w)$ & $\begin{array}{l}\text { Control: } \mathrm{CaP} 800 \mathrm{mg} / \mathrm{m}^{2} \times 2 / \mathrm{d} \mathrm{d} 1-\mathrm{d} 14 \text { and d22-d25 } \\
\text { Exp: CaP } 800 \mathrm{mg} / \mathrm{m}^{2} \times 2 / \mathrm{d} \mathrm{d} 1-\mathrm{d} 14 \text { and d22-d25 + oxaliplatin } \\
60 \mathrm{mg} / \mathrm{m}^{2} / \mathrm{d} \mathrm{d} 1, \mathrm{~d} 8, \mathrm{~d} 22 \text { and } \mathrm{d} 29\end{array}$ & $\begin{array}{c}\text { 5FU bolus } 400 \mathrm{mg} / \mathrm{m}^{2} / \mathrm{d} \cdot+5 \mathrm{FU} \\
2400 \mathrm{mg} / \mathrm{m}^{2} \mathrm{~d} 1-\mathrm{d} 2+\text { oxaliplatin } \\
85 \mathrm{mg} / \mathrm{m}^{2} / \mathrm{d}+\text { leucovorin } \\
400 \mathrm{mg} / \mathrm{m}^{2} \times 6-8 \text { cycles }\end{array}$ & 48.7 months \\
\hline Total & & & $\begin{array}{c}\text { Control }=3055 \\
\quad \text { Exp }=2727\end{array}$ & & & & \\
\hline
\end{tabular}

Exp = Experimental $\mathrm{CaP}=$ Capecitabine; $\mathrm{d}=$ day; $\mathrm{w}=$ week Gy = Gray; $\mathrm{NR}=$ Not reported.

\subsection{Disease-Free Survival}

All seven trials reported disease-free survival (DFS) in a total of 5782 patients. DFS was statistically significantly improved by the addition of oxaliplatin in the meta-analysis $\left(\mathrm{HR}=0.90,95 \%\right.$ CI: 0.81-0.99; $p=0.03, \mathrm{I}^{2}=0 \%$ (Figure 1$)$.

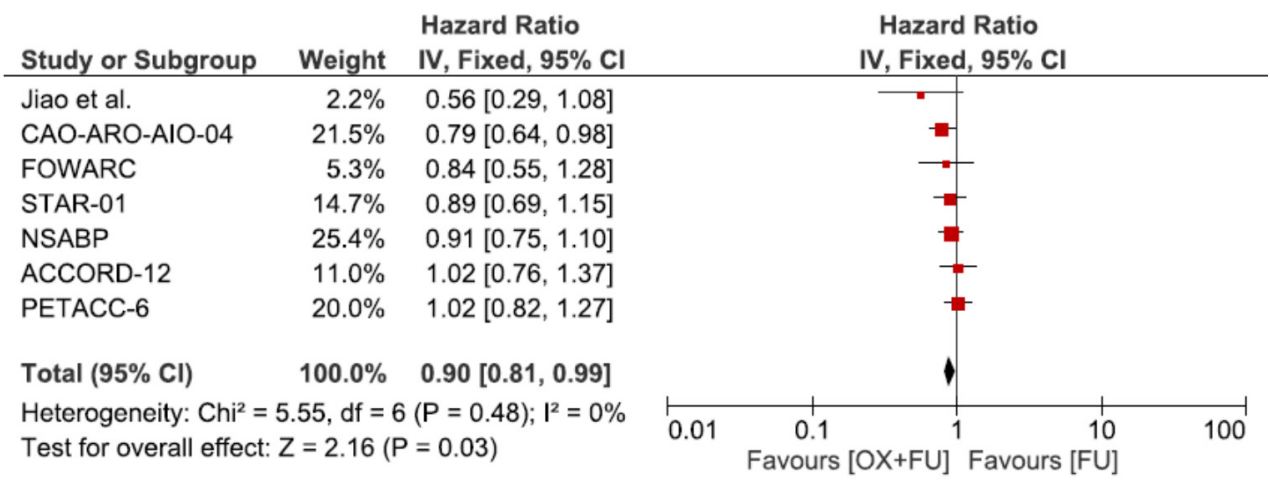

Figure 1. Forest plot of hazard ratio for disease free survival.

\subsection{Overall Survival}

Seven trials reported overall survival (OS) corresponding to 5782 patients. No statistically significant difference was observed for OS (HR $=0.9495 \%$ CI: $0.83-1.06 ; p=0.53$, $\mathrm{I}^{2}=0 \%$ (Figure 2). 


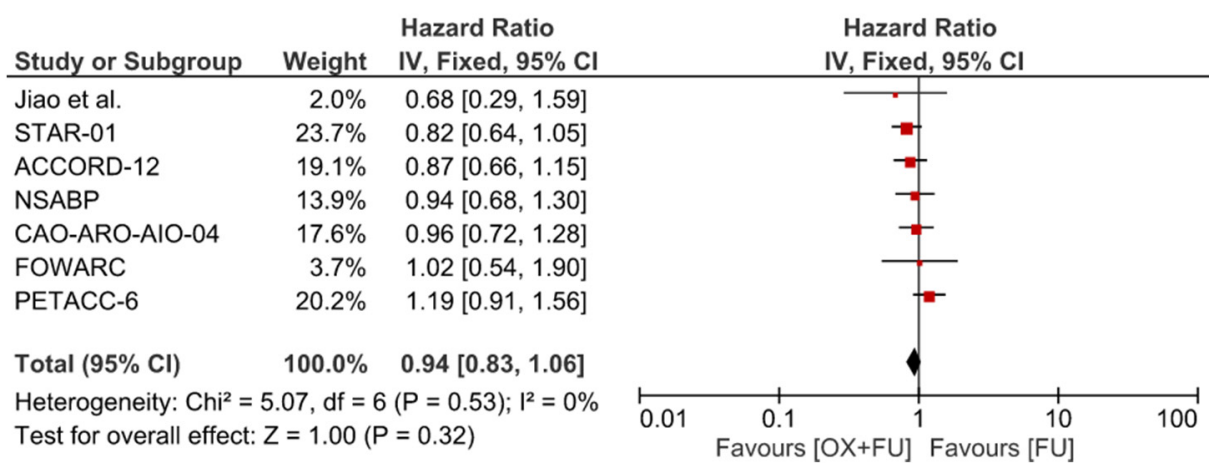

Figure 2. Forest plot of hazard ratio for overall survival.

\subsection{Pathological Complete Response}

Seven trials reported pathological complete response rate after neoadjuvant chemoradiotherapy corresponding to 5386 patients. The pathological complete response rate ranged from $13.4 \%$ to $27.5 \%$ in the oxaliplatin $+5 \mathrm{FU}$ group and from $11.3 \%$ to $19.4 \%$ in the $5 \mathrm{FU}$ only group, with a significantly higher rate in the oxaliplatin $+5 \mathrm{FU}$ group $(17.9 \%$ vs. $14.7 \%$, $\mathrm{RR}=1.21,95 \%$ CI: 1.07-1.37, $p=0.002, \mathrm{I}^{2}=14 \%$ ) (Figure 3).

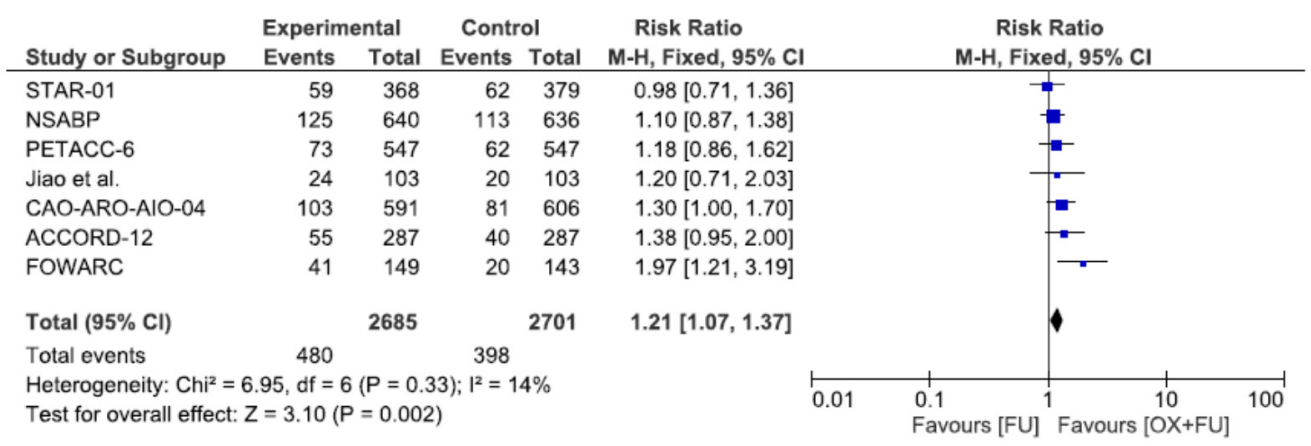

Figure 3. Forest plot of risk ratio for pathological complete response.

\subsection{Local Recurrence}

Four trials reported local recurrence rate corresponding to 3635 patients. The local recurrence rate ranged from $3.0 \%$ to $11.5 \%$ in the oxaliplatin group and from $4.7 \%$ to $12.1 \%$ in the fluoropyrimidine only group, without statistical significance $(7.0 \%$ vs. $8.1 \%$, $\mathrm{RR}=0.86,95 \%$ CI: 0.68-1.08, $p=0.19, \mathrm{I}^{2}=0 \%$ ) (Figure 4 ).

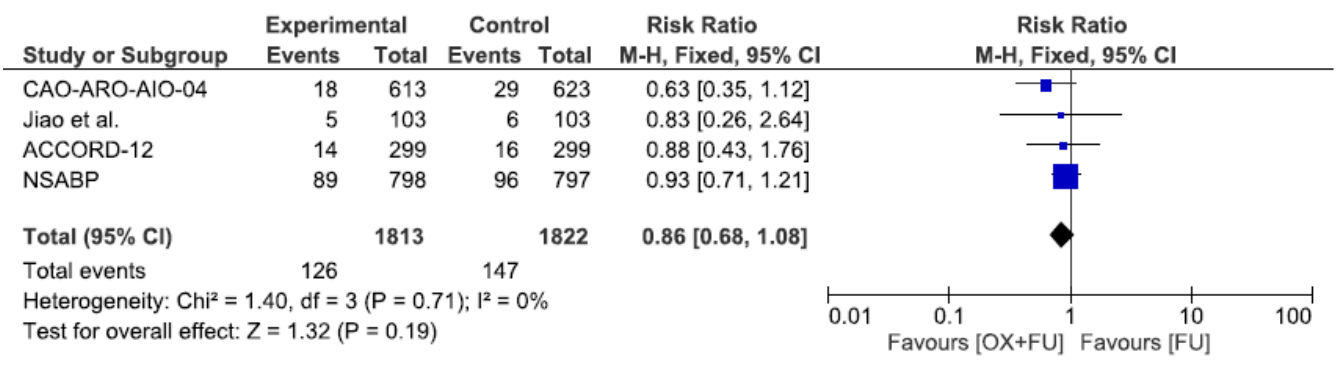

Figure 4. Forest plot of risk ratio for local recurrence.

\subsection{Metastatic Progression}

Metastatic progression rate was reported in three studies, corresponding to a total of 2040 patients. The metastatic progression rate ranged from $16.5 \%$ to $22.1 \%$ in the oxaliplatin $+5 \mathrm{FU}$ group and from $22.5 \%$ to $28.2 \%$ in the $5 \mathrm{FU}$ only group, with a significantly lower rate in the oxaliplatin $+5 \mathrm{FU}$ group $(18.7 \%$ vs. $23.6 \%$, RR $=0.79,95 \% \mathrm{CI}: 0.67-0.94$, $p=0.007, \mathrm{I}^{2}=2 \%$ ) (Figure 5). 


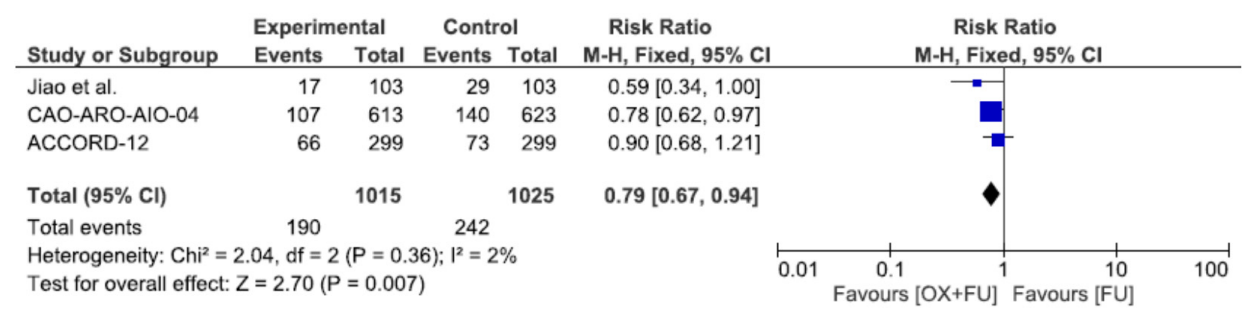

Figure 5. Forest plot of risk ratio for metastatic progression.

\subsection{R0 Resection}

R0 resection rate was reported in six studies, corresponding to a total of 4097 patients. The $\mathrm{R} 0$ resection rate ranged from $86.3 \%$ to $97.1 \%$ in the oxaliplatin $+5 \mathrm{FU}$ group and from $87.3 \%$ to $95.2 \%$ in the $5 \mathrm{FU}$ only group, without statistical significance $(92.5 \%$ vs. $91.9 \%$, $\mathrm{RR}=1.05,95 \%$ CI: 0.66-1.67, $p=0.83, \mathrm{I}^{2}=69 \%$ ) (Figure 6).

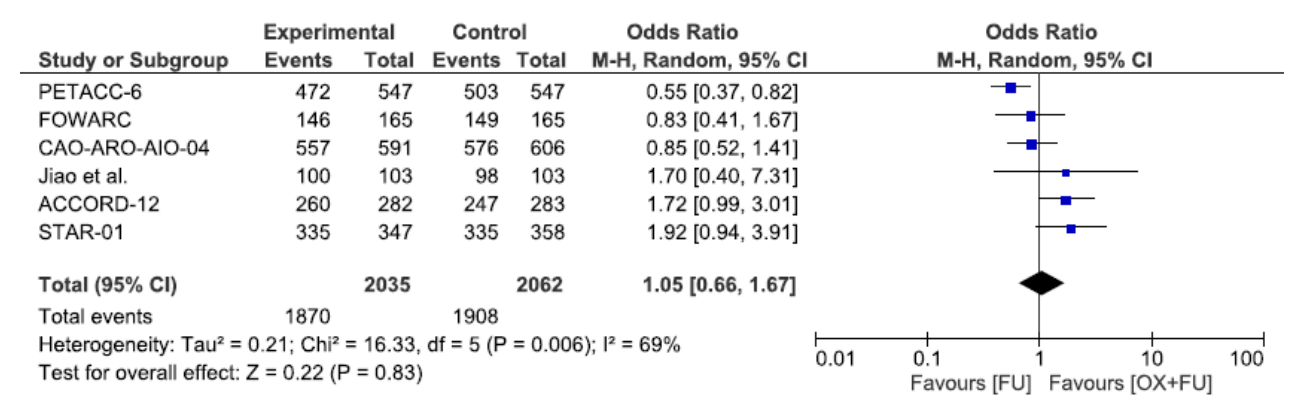

Figure 6. Forest plot of odds ratio for R0 Resection.

\subsection{Toxicity}

Severe toxicities (grade 3-4) were reported in six studies, corresponding to a total of 5125 patients. Severe toxicity rates ranged from $21.4 \%$ to $40.1 \%$ in the oxaliplatin $+5 \mathrm{FU}$ group and from $7.6 \%$ to $25.5 \%$ in the $5 \mathrm{FU}$ group, without statistical significance $(30.7 \%$ vs. $17.7 \%, \mathrm{RR}=1.92,95 \% \mathrm{CI}: 1.40-2.64, p<0.0001, \mathrm{I}^{2}=87 \%$ ) (Figure 7 ).

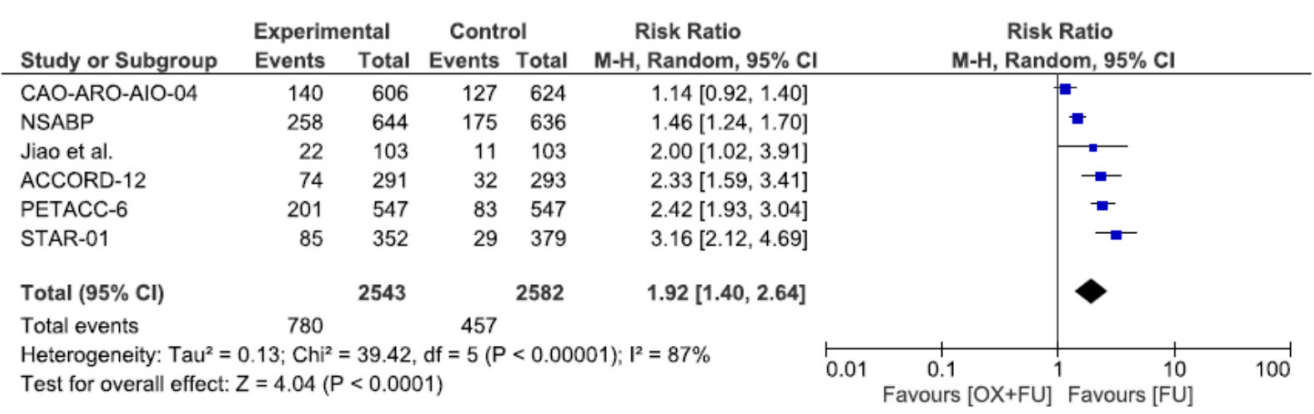

Figure 7. Forest plot of risk ratio for grade 3 or 4 toxicity.

\subsection{Hematological Toxicity}

Severe hematological toxicities (grade 3-4) were reported in four studies, corresponding to a total of 2350 patients. Severe hematological toxicity rates ranged from $4.8 \%$ to $20.6 \%$ in the oxaliplatin $+5 \mathrm{FU}$ group and from $2.9 \%$ to $14.6 \%$ in the $5 \mathrm{FU}$ group, without statistical significance $\left(7.3 \%\right.$ vs. $6.3 \%, \mathrm{RR}=1.16,95 \% \mathrm{CI}: 0.87-1.57, p=0.31, \mathrm{I}^{2}=0 \%$ ) (Figure 8 ). 


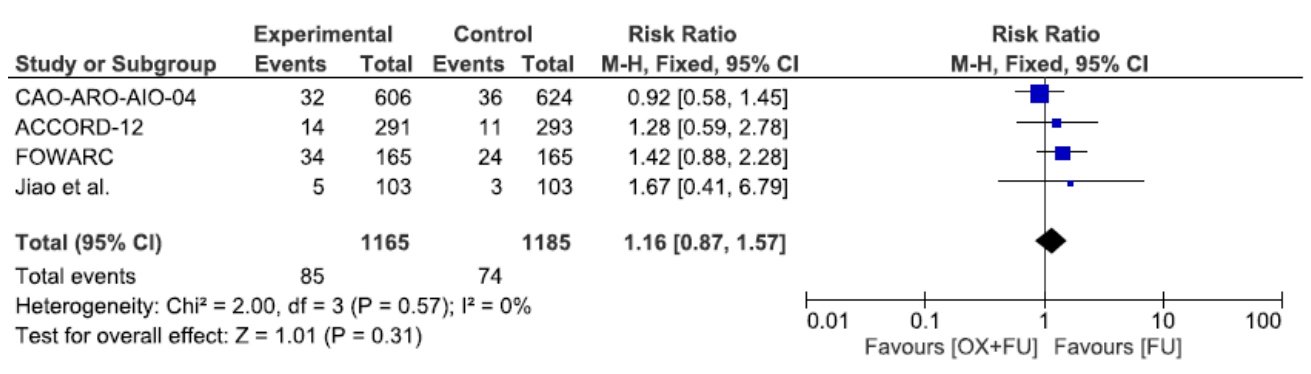

Figure 8. Forest plot of risk ratio for hematological toxicity.

\subsection{Digestive Toxicity}

Severe diarrhea toxicities (grade 3-4) were reported in seven studies, corresponding to a total of 5455 patients. Severe diarrhea toxicity rates ranged from $12.1 \%$ to $18.5 \%$ in the oxaliplatin $+5 \mathrm{FU}$ group and from $3.1 \%$ to $9.7 \%$ in the $5 \mathrm{FU}$ only group, with a significantly higher rate in the oxaliplatin $+5 \mathrm{FU}$ group $(15.1 \%$ vs. $6.4 \%, \mathrm{RR}=2.41,95 \%$ CI: $1.74-3.32$, $p<0.00001, \mathrm{I}^{2}=68 \%$ ) (Figure 9).

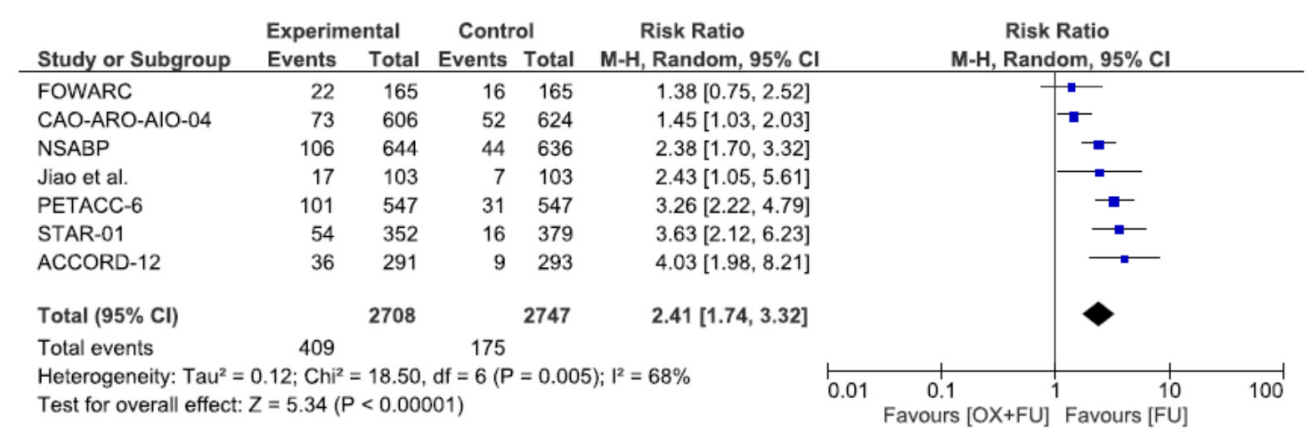

Figure 9. Forest plot of risk ratio for digestive toxicity.

\subsection{Postoperative Complications}

Postoperative complication rates were reported in five studies, corresponding to a total of 4818 patients. Postoperative complication rates ranged from $22.1 \%$ to $43.7 \%$ in the fluoropyrimidine only group and from $23.7 \%$ to $47.0 \%$ in the oxaliplatin group, without statistical significance $\left(3.8 \%\right.$ vs. $3.6 \%, \mathrm{RR}=1.05,95 \% \mathrm{CI}: 0.98-1.13, \mathrm{P}=0.15, \mathrm{I}^{2}=0 \%$ ) (Figure 10).

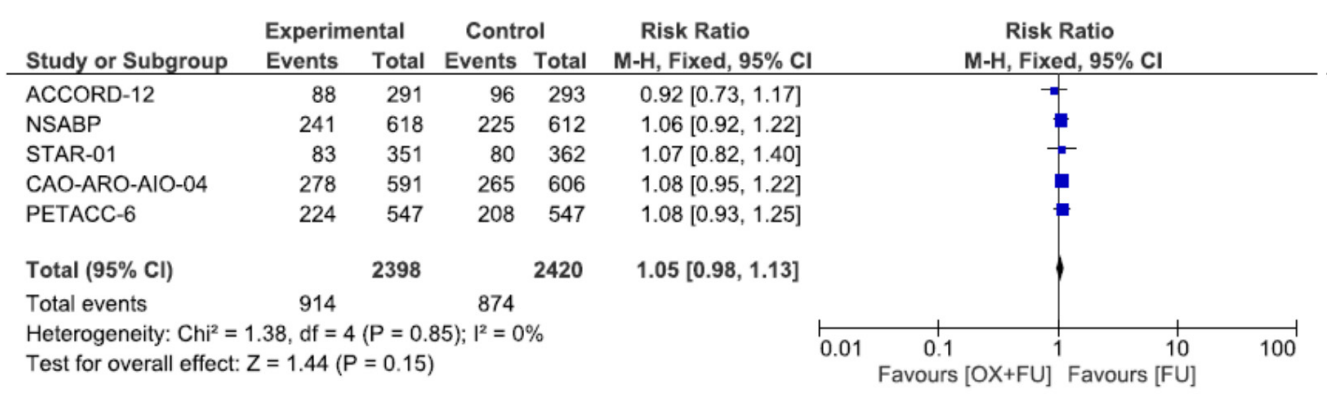

Figure 10. Forest plot of risk ratio for postoperative complications.

\subsection{Permanent Stoma}

We did not find any significative difference between the two groups regarding permanent stoma incidence rate: $\mathrm{RR}=1.01(0.92-1.12)$.

\subsection{Death within 60 Days}

We did not find any significative difference between the two groups regarding death incidence within 60 days after surgery: $R R=0.83(0.35-2.00)$. 


\section{Discussion}

We performed a meta-analysis evaluating the effect of preoperative radiotherapy combined with fluoropyrimidine (capecitabine or 5FU) with or without oxaliplatin. As the aim of our study was to assess the radiosensitizing effect of oxaliplatin, we excluded the ADORE study from our meta-analysis, as it mainly assessed the benefit of postoperative treatment [21]. Indeed, the benefit of postoperative chemotherapy in rectal cancer is unclear despite no decrease in dose intensity of oxaliplatin in postoperative regimens as compared with colon cancer patients [22]. Conversely, oxaliplatin in the neoadjuvant setting has a growing interest in alternative approaches with less morbidity, including the organpreserving watch-and-wait strategy, in which surgery is omitted in patients who have achieved a clinical complete response [23].

One of the limitations of the meta-analysis is that not only the doses/schedules of oxaliplatin differed between the trials but also the doses/schedules of $5 \mathrm{FU} /$ capecitabine differed between the trials and also within the same trial (CAO/ARO AIO-04). This could explain why some trials were significantly positive and others were not.

In the $\mathrm{CAO} / \mathrm{ARO} / \mathrm{AIO}-04$ trial, patients received oxaliplatin not only during neoadjuvant chemoradiotherapy but also during adjuvant chemotherapy, and therefore patients received a higher cumulative total dose of oxaliplatin than in the other studies (1000 vs. $250-360 \mathrm{mg} / \mathrm{m}^{2}$ ). In this trial, pathological complete response (pCR) rate and 3-year DFS were improved. Moreover, in a retrospective study, Chang et al. showed that cumulative oxaliplatin dose (COD) $<460 \mathrm{mg} / \mathrm{m}^{2}$ was an independent predictor of poorer overall metastasis-free and disease-free survival. However, a COD $460 \mathrm{mg} / \mathrm{m}^{2}$ increased the incidence of acute toxicities from $38.4 \%$ to $70.8 \%(p<0.001)$ [24].

The primary endpoint for most studies analyzed in our meta-analysis was DFS (Jiao, FOWARC, CAO/ARO/AIO-04, PETACC6). It was OS in STAR-01 and Jiao, local-regional tumor control in the NSABP study, and pathologic complete response (ypCR) in ACCORD 12 (Table 2). In our meta-analysis, we found that the addition of oxaliplatin to radiotherapy increased metastasis-free survival and pathological complete response rate. Zheng's metaanalysis of eight studies found an additional benefit in terms of local relapse [6].

Table 2. Study-reported endpoints.

\begin{tabular}{cccccccc}
\hline Study & OS & DFS & pCR & Local-Regional Recurrence & Metastatic Progression & R0 & Toxicity \\
\hline NSABP-R04 & $\bullet$ & $\bullet$ & $\bullet$ & $\bullet *$ & $\bullet$ & $\bullet$ \\
STAR-01 & $\bullet *$ & $\bullet$ & $\bullet$ & $\bullet$ & $\bullet$ & $\bullet$ \\
FOWARC & $\bullet$ & $\bullet *$ & $\bullet$ & $\bullet$ & $\bullet$ & $\bullet$ \\
ACCORD-12 & $\bullet$ & $\bullet$ & $\bullet *$ & $\bullet$ & $\bullet$ & $\bullet$ \\
CAO/ARO/AIO-04 & $\bullet$ & $\bullet *$ & $\bullet$ & $\bullet$ & $\bullet$ \\
PETACC-6 & $\bullet$ & $\bullet *$ & $\bullet$ & $\bullet$ & $\bullet$ & $\bullet$ \\
Jiao et al. [18] & $\bullet *$ & $\bullet *$ & $\bullet$ & $\bullet$ & $\bullet$ & $\bullet$ \\
\hline
\end{tabular}

* primary endpoint; OS: overall survival; DFS: disease-free survival; pCR: pathological complete response; R0: negative resection margins. - endpoint evaluated; $\bullet$ endpoint not evaluated.

\subsection{Comparison with Others Meta-Analyses}

Several meta-analyses have been previously published between 2013 and 2018 (Table 3). These studies addressed the same question of the benefit of adding oxaliplatin to the standard treatment of preoperative radiotherapy combined with a fluoropyrimidine.

The short follow-up of previously published meta-analyses could preclude the translation of improved DFS on OS. The latest meta-analysis was published more than 3 years ago, our meta-analysis incorporated the latest update of the FOWARC study results published in 2019 and the PETACC-6 study results published in 2021, with a median follow-up of 68 months vs. 31 months in the previous publication in 2013. One by one, the studies included in our meta-analysis did not find a statistically significant benefit in terms of DFS. However, our meta-analysis found a significant benefit in terms of DFS. This could be explained by the updating of data from the FOWARC study. 
Table 3. Previous meta-analysis results.

\begin{tabular}{|c|c|c|c|c|c|c|c|c|c|c|c|}
\hline Meta-Analysis & Years & Studies & $\mathrm{n}$ & os & DFS & MFS & $\mathrm{pCR}$ & Ro & Local Failure & Colostomy & Toxicity \\
\hline Current study & 2021 & 7 & 5782 & - & + & + & + & - & - & - & + \\
\hline Huttner & 2018 & 5 & 5599 & - & - & + & + & NR & - & NR & + \\
\hline De Felice & 2017 & 4 & 3310 & - & - & + & NR & NR & - & NR & NR \\
\hline Thavaneswaran & 2017 & 7 & 4444 & - & + & + & + & - & + & & + \\
\hline Zheng & 2017 & 8 & 5597 & - & + & + & + & & + & - & + \\
\hline $\mathrm{Fu}$ & 2017 & 8 & 6103 & - & $\begin{array}{l}+(3 y) \\
-(5 y)\end{array}$ & $\mathrm{NR}$ & + & $\mathrm{NR}$ & NR & - & + \\
\hline Yang & 2016 & 7 & 5415 & NR & + & + & + & - & - & NR & + \\
\hline Zhao & 2016 & 4 & 2793 & - & + & $\mathrm{NR}$ & NR & NR & NR & NR & + \\
\hline Resende & 2015 & 4 & 3875 & - & - & - & + & - & - & - & + \\
\hline An & 2013 & 4 & 3863 & NR & NR & + & + & NR & NR & - & + \\
\hline
\end{tabular}

Despite the lasting benefit in DFS, our meta-analysis did not show a benefit of the addition of oxaliplatin in terms of overall survival. The main weakness of our study is that our meta-analysis was performed on published data and not on individual data. However, all selected studies were phase 3 studies conducted by cooperating clinical research groups producing reliable data.

\subsection{Toxicity}

Similar to other meta-analyses, we found an increase in toxicity with the addition of oxaliplatin.

Oxaliplatin increased hematological and gastrointestinal toxicity in comparison with fluoropyrimidine-based chemotherapy alone. These toxicities are manageable but require careful monitoring, especially diarrhea, which can be responsible for sepsis or dehydration. In clinical practice, this toxicity does not appear to be a definitive obstacle to the use of oxaliplatin in combination with radiotherapy.

\subsection{Perspectives}

Oxaliplatin is a major drug in digestive oncology. It is active in many cancers such as stomach, esophagus, pancreatic, and colon/rectal cancers. Given the effectiveness of fluoropyrimidine-based preoperative chemoradiotherapy in local control, the main criterion in improving the treatment of locally advanced rectal cancer should be distant control, as metastases still occur in about $30 \%$ of patients. The other improvement to be made would be to increase the rate of pathological complete response of the rectal tumor in order to avoid surgery and thus the risk of developing LARS syndrome or undergoing definitive colostomy, as could happen in abdominal-perineal amputation for very low rectal cancers.

The improvement in progression-free survival and pathological complete response rate observed in our meta-analysis with the concomitant addition of oxaliplatin to standard chemoradiotherapy must be weighed against the significant improvement in metastasisfree survival and histological complete response rate without redhibitory toxicity obtained with total neoadjuvant therapy combining induction FOLFIRINOX chemotherapy followed by chemoradiotherapy, as in the PRODIGE 23 randomized trial or with short course radiotherapy followed by oxaliplatin-based consolidation chemotherapy, as in the RAPIDO randomized trial recently published $[25,26]$.

The administration of an optimal chemotherapy preoperatively and sequentially to the concomitant (chemo)-radiotherapy has made it possible to decrease the rate of metastatic progression from $30 \%$ to around $20 \%$ and to achieve a rate of complete pathological response around $30 \%$, with very acceptable tolerance.

In accordance with these data, the total neoadjuvant therapy (TNT) approach could become one of the standard treatments for locally advanced rectal cancer. The question of the feasibility of a TNT associated with concomitant chemoradiotherapy potentiated by oxaliplatin remains, especially given radiotherapy technical progress, such as VMAT 
that decreases intestinal toxicity [27]. This approach could be interesting to evaluate in the context of a watch-and-wait organ conservation strategy.

\section{Conclusions}

Our meta-analysis with long-term results from the randomized studies showed a benefit of the addition of OXP + 5FU regiment in terms of DFS, metastatic progression, and $\mathrm{pCR}$ rate that did not translate to improved OS. It remains necessary to identify which patients benefit most from the addition of oxaliplatin.

Author Contributions: Conceptualization, G.D.G., M.M. and L.Q.; Formal analysis, T.L. and L.Q.; Methodology, T.L. and L.Q.; Project administration, T.L.; Supervision, L.Q.; Validation, G.D.G., M.M. and L.Q.; Writing-original draft, G.D.G., T.L. and L.Q.; Writing-review \& editing, M.A.B. All authors have read and agreed to the published version of the manuscript.

Funding: This research received no external funding.

Conflicts of Interest: The authors declare that they have no known competing financial interest or personal relationships that could have appeared to influence the work reported in this paper.

\section{Appendix A}

628 records identified through database searching
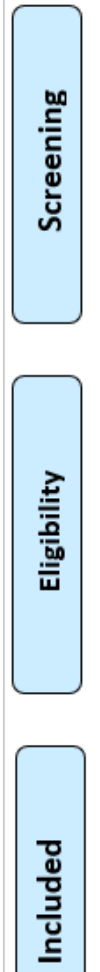

12 records identified through other sources

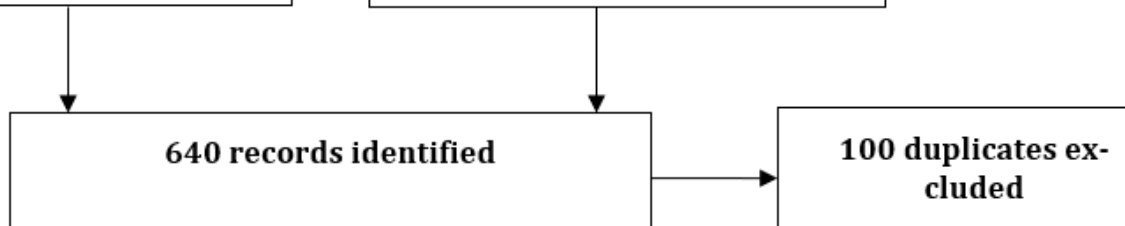
cluded

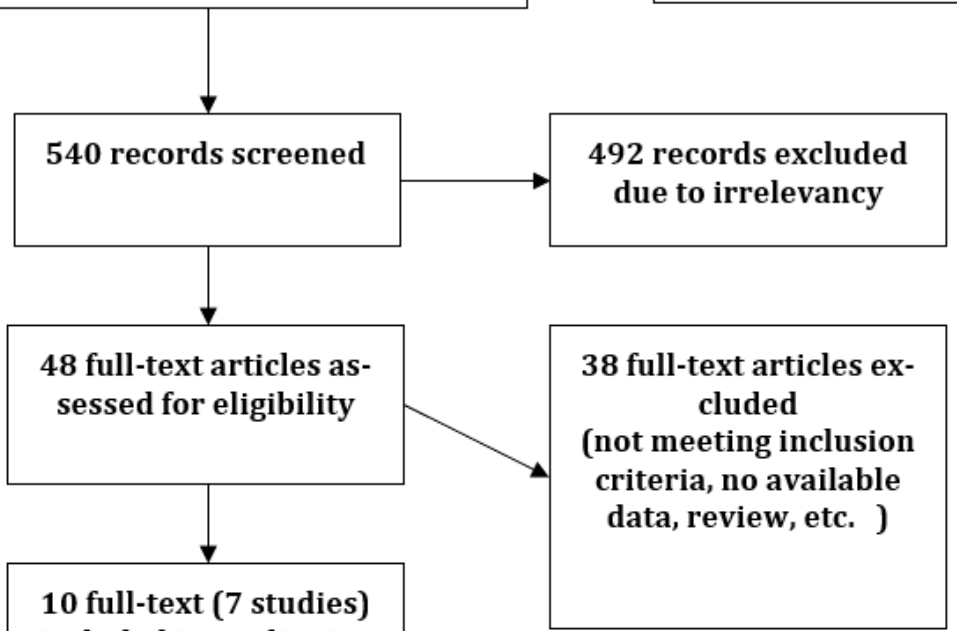

included in qualitative synthesis

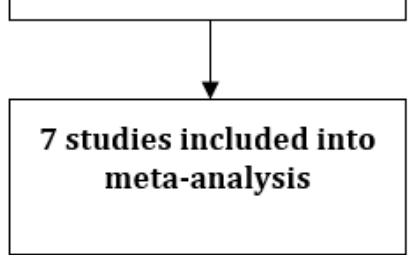

Figure A1. Prisma flow diagram. 


\section{References}

1. Bray, F.; Ferlay, J.; Soerjomataram, I.; Siegel, R.L.; Torre, L.A.; Jemal, A. Global cancer statistics 2018: GLOBOCAN estimates of incidence and mortality worldwide for 36 cancers in 185 countries. CA Cancer J. Clin. 2018, 68, 394-424. [CrossRef]

2. Gérard, J.-P.; Conroy, T.; Bonnetain, F.; Bouché, O.; Chapet, O.; Closon-Dejardin, M.-T.; Untereiner, M.; LeDuc, B.; Francois, É.; Maurel, J.; et al. Preoperative radiotherapy with or without concurrent fluorouracil and leucovorin in T3-4 rectal cancers: Results of FFCD 9203. J. Clin. Oncol. Off. J. Am. Soc. Clin. Oncol. 2006, 24, 4620-4625. [CrossRef] [PubMed]

3. Bosset, J.-F.; Collette, L.; Calais, G.; Mineur, L.; Maingon, P.; Radosevic-Jelic, L.; Daban, A.; Bardet, E.; Beny, A.; Ollier, J.-C. Chemotherapy with preoperative radiotherapy in rectal cancer. N. Engl. J. Med. 2006, 355, 1114-1123. [CrossRef]

4. Zhu, A.X.; Willett, C.G. Chemotherapeutic and biologic agents as radiosensitizers in rectal cancer. Semin. Radiat. Oncol. 2003, 13, 454-468. [CrossRef]

5. Yang, Y.-J.; Cao, L.; Li, Z.; Zhao, L.; Wu, H.-F.; Yue, D.; Yang, J.-L.; Zhou, Z.-R.; Liu, S.-X. Fluorouracil-based neoadjuvant chemoradiotherapy with or without oxaliplatin for treatment of locally advanced rectal cancer: An updated systematic review and meta-analysis. Oncotarget 2016, 7, 45513-45524. [CrossRef]

6. Zheng, J.; Feng, X.; Hu, W.; Wang, J.; Li, Y. Systematic review and meta-analysis of preoperative chemoradiotherapy with or without oxaliplatin in locally advanced rectal cancer. Medicine 2017, 96, e6487. [CrossRef] [PubMed]

7. An, X.; Lin, X.; Wang, F.-H.; Goodman, K.; Cai, P.-Q.; Kong, L.-H.; Fang, Y.-J.; Gao, Y.-H.; Lin, J.-Z.; Wan, D.-S.; et al. Short term results of neoadjuvant chemoradiotherapy with fluoropyrimidine alone or in combination with oxaliplatin in locally advanced rectal cancer: A meta analysis. Eur. J. Cancer 2013, 49, 843-851. [CrossRef] [PubMed]

8. Fu, X.-L.; Fang, Z.; Shu, L.-H.; Tao, G.-Q.; Wang, J.-Q.; Rui, Z.-L.; Zhang, Y.-J.; Tian, Z.-Q. Meta-analysis of oxaliplatin-based versus fluorouracil-based neoadjuvant chemoradiotherapy and adjuvant chemotherapy for locally advanced rectal cancer. Oncotarget 2017, 8, 34340-34351. [CrossRef]

9. Hüttner, F.J.; Probst, P.; Kalkum, E.; Hackbusch, M.; Jensen, K.; Ulrich, A.; Debus, J.; Jäger, D.; Diener, M.K. Addition of Platinum Derivatives to Fluoropyrimidine-Based Neoadjuvant Chemoradiotherapy for Stage II/III Rectal Cancer: Systematic Review and Meta-Analysis. J. Natl. Cancer Inst. 2019, 111, 887-902. [CrossRef] [PubMed]

10. Resende, H.M.; Jacob, L.F.P.; Quinellato, L.V.; Matos, D.; da Silva, E.M. Combination chemotherapy versus single-agent chemotherapy during preoperative chemoradiation for resectable rectal cancer. Cochrane Database Syst. Rev. 2015. [CrossRef]

11. Aschele, C.; Cionini, L.; Lonardi, S.; Pinto, C.; Cordio, S.; Rosati, G.; Artale, S.; Tagliagambe, A.; Ambrosini, G.; Rosetti, P.; et al. Primary tumor response to preoperative chemoradiation with or without oxaliplatin in locally advanced rectal cancer: Pathologic results of the STAR-01 randomized phase III trial. J. Clin. Oncol. Off. J. Am. Soc. Clin. Oncol. 2011, 29, 2773-2780. [CrossRef]

12. Gérard, J.P.; Azria, D.; Gourgou-Bourgade, S.; Martel-Laffay, I.; Hennequin, C.; Etienne, P.L.; Vendrely, V.; François, E.; de La Roche, G.; Bouché, O.; et al. Comparison of two neoadjuvant chemoradiotherapy regimens for locally advanced rectal cancer: Results of the phase III trial ACCORD 12/0405-Prodige 2. J. Clin. Oncol. Off. J. Am. Soc. Clin. Oncol. 2010, 28, 1638-1644. [CrossRef]

13. Gérard, J.P.; Azria, D.; Gourgou-Bourgade, S.; Martel-Lafay, I.; Hennequin, C.; Etienne, P.L.; Vendrely, V.; François, E.; de La Roche, G.; Bouché, O.; et al. Clinical outcome of the ACCORD 12/0405 PRODIGE 2 randomized trial in rectal cancer. J. Clin. Oncol. Off. J. Am. Soc. Clin. Oncol. 2012, 30, 4558-4565. [CrossRef] [PubMed]

14. Azria, D.A.; Doyen, J.; Jarlier, M.; Martel-Lafay, I.; Hennequin, C.; Etienne, P.; Vendrely, V.; François, E.; de La Roche, G.; Bouché, O.; et al. Late toxicities and clinical outcome at 5 years of the ACCORD 12/0405-PRODIGE 02 trial comparing two neoadjuvant chemoradiotherapy regimens for intermediate-risk rectal cancer. Ann. Oncol. Off. J. Eur. Soc. Med. Oncol. 2017, 28, 2436-2442. [CrossRef]

15. O'Connell, M.J.; Colangelo, L.H.; Beart, R.W.; Petrelli, N.J.; Allegra, C.J.; Sharif, S.; Pitot, H.C.; Shields, A.F.; Landry, J.C.; Ryan, D.P.; et al. Capecitabine and oxaliplatin in the preoperative multimodality treatment of rectal cancer: Surgical end points from National Surgical Adjuvant Breast and Bowel Project trial R-04. J. Clin. Oncol. Off. J. Am. Soc. Clin. Oncol. 2014, 32, 1927-1934. [CrossRef] [PubMed]

16. Allegra, C.J.; Yothers, G.; O'Connell, M.J.; Beart, R.W.; Wozniak, T.F.; Pitot, H.C.; Shields, A.F.; Landry, J.C.; Ryan, D.P.; Arora, A.; et al. Neoadjuvant 5-FU or Capecitabine Plus Radiation with or without Oxaliplatin in Rectal Cancer Patients: A Phase III Randomized Clinical Trial. J. Natl. Cancer Inst. 2015, 107, djv248. [CrossRef]

17. Rödel, C.; Graeven, U.; Fietkau, R.; Hohenberger, W.; Hothorn, T.; Arnold, D.; Hofheinz, R.-D.; Ghadimi, M.; A Wolff, H.; LangWelzenbach, M.; et al. Oxaliplatin added to fluorouracil-based preoperative chemoradiotherapy and postoperative chemotherapy of locally advanced rectal cancer (the German CAO/ARO/AIO-04 study): Final results of the multicentre, open-label, randomised, phase 3 trial. Lancet Oncol. 2015, 16, 979-989. [CrossRef]

18. Jiao, D.; Zhang, R.; Gong, Z.; Liu, F.; Chen, Y.; Yu, Q.; Sun, L.; Duan, H.; Zhu, S.; Liu, F.; et al. Fluorouracil-based preoperative chemoradiotherapy with or without oxaliplatin for stage II/III rectal cancer: A 3-year follow-up study. Chin. J. Cancer Res. 2015, 27, 588-596. [PubMed]

19. Deng, Y.; Chi, P.; Lan, P.; Wang, L.; Chen, W.; Cui, L.; Chen, D.; Cao, J.; Wei, H.; Peng, X.; et al. Neoadjuvant Modified FOLFOX6 With or Without Radiation versus Fluorouracil Plus Radiation for Locally Advanced Rectal Cancer: Final Results of the Chinese FOWARC Trial. JJ. Clin. Oncol. Off. J. Am. Soc. Clin. Oncol. 2019, 37, 3223-3233. [CrossRef] [PubMed] 
20. Schmoll, H.-J.; Stein, A.; Van Cutsem, E.; Price, T.; Hofheinz, R.D.; Nordlinger, B.; Daisne, J.-F.; Janssens, J.; Brenner, B.; Reinel, H.; et al. Pre- and Postoperative Capecitabine Without or With Oxaliplatin in Locally Advanced Rectal Cancer: PETACC 6 Trial by EORTC GITCG and ROG, AIO, AGITG, BGDO, and FFCD. J. Clin. Oncol. Off. J. Am. Soc. Clin. Oncol. 2021, 39, 17-29. [CrossRef]

21. Hong, Y.S.; Kim, S.Y.; Lee, J.S.; Nam, B.-H.; Kim, K.-P.; Kim, J.E.; Park, Y.S.; Park, J.O.; Baek, J.Y.; Kim, T.-Y.; et al. Oxaliplatin-Based Adjuvant Chemotherapy for Rectal Cancer after Preoperative Chemoradiotherapy (ADORE): Long-Term Results of a Randomized Controlled Trial. J. Clin. Oncol. Off. J. Am. Soc. Clin. Oncol. 2019, 37, 3111-3123. [CrossRef]

22. Spałek, M.; Michalski, K.; Bujko, K.; Wyrwicz, L. Association between Preoperative Pelvic Irradiation and Toxicity of Subsequent Chemotherapy in Rectal Cancer. Oncol. Res. Treat. 2019, 42, 497-505. [CrossRef] [PubMed]

23. López-Campos, F.; Martín-Martín, M.; Fornell-Pérez, R.; García-Pérez, J.C.; Die-Trill, J.; Fuentes-Mateos, R.; López-Durán, S.; Domínguez-Rullán, J.; Ferreiro, R.; Riquelme-Oliveira, A.; et al. Watch and wait approach in rectal cancer: Current controversies and future directions. World J. Gastroenterol. 2020, 26, 4218-4239. [CrossRef]

24. Chang, H.; Tao, Y.-L.; Jiang, W.; Chen, C.; Liu, S.-L.; Ye, W.-J.; Gao, Y.-H. Optimize the dose of oxaliplatin for locally advanced rectal cancer treated with neoadjuvant chemoradiotherapy followed by radical surgery and adjuvant chemotherapy. BMC Cancer 2020, 20, 498. [CrossRef] [PubMed]

25. Conroy, T.; Lamfichekh, N.; Etienne, P.-L.; Rio, E.; Francois, E.; Mesgouez-Nebout, N.; Vendrely, V.; Artignan, X.; Bouché, O.; Gargot, D.; et al. Total neoadjuvant therapy with mFOLFIRINOX versus preoperative chemoradiation in patients with locally advanced rectal cancer: Final results of PRODIGE 23 phase III trial, a UNICANCER GI trial. J. Clin. Oncol. 2020, 38 (Suppl. S15), 4007. [CrossRef]

26. Bahadoer, R.R.; A Dijkstra, E.; van Etten, B.; Marijnen, C.A.M.; Putter, H.; Kranenbarg, E.M.-K.; Roodvoets, A.G.H.; Nagtegaal, I.D.; Beets-Tan, R.G.H.; Blomqvist, L.K.; et al. Short-course radiotherapy followed by chemotherapy before total mesorectal excision (TME) versus preoperative chemoradiotherapy, TME, and optional adjuvant chemotherapy in locally advanced rectal cancer (RAPIDO): A randomised, open-label, phase 3 trial. Lancet Oncol. 2021, 22, 29-42. [CrossRef]

27. Dröge, L.H.; Weber, H.E.; Guhlich, M.; Leu, M.; Conradi, L.-C.; Gaedcke, J.; Hennies, S.; Herrmann, M.K.; Rave-Fränk, M.; Wolff, H.A. Reduced toxicity in the treatment of locally advanced rectal cancer: A comparison of volumetric modulated arc therapy and 3D conformal radiotherapy. BMC Cancer 2015, 15, 750. [CrossRef] 